\title{
Comparison of Children's Motor Performances by Age and Gender
}

\author{
Mehmet Imamoğlu*, Orhan Ahmet Şener \\ Faculty of Sport Sciences, Sinop University, Turkey
}

Copyright $\subseteq 2019$ by authors, all rights reserved. Authors agree that this article remains permanently open access under the terms of the Creative Commons Attribution License 4.0 International License

\begin{abstract}
The aim of this study is to investigate motor performance of children by age and gender. A total of 160 children ( 80 girls and 80 boys) participated in this study voluntarily. Children were divided into 4 groups according to their gender (girls and boys) and age (11 and 12 years). One Way ANOVA and LSD tests were used. There were statistically significant differences in height and weight in all groups. Sit and reach, sit-up, 30 meter sprint and bent arm hang tests results showed that there were statistically significant differences between girls and boys in all age groups. There was no statistically significant difference in plate tapping test. According to the results of the flamingo balance test, a statistically significant difference was found between the age groups. The standing long jump results from 12 year old boys and 11 year old girls are more than the 11 year old boys and 12 year old girls. Participants anthropometric and motor performance test results were among the normal values. Physical characteristics and motor performance parameters vary by age and gender.
\end{abstract}

Keywords Motor Performance, Eurofit Tests, Sport

\section{Introduction}

Scientific research points out the importance of having a healthy lifestyle and doing physical activities from childhood to adulthood. The positive effects of physical activities and the negative effects of sedentary lifestyle have encouraged researchers to focus on the physical characteristics of children [1].

Participate in sporting events; improves the general health of people who are the basic elements of social, cultural and economic progress, increase their ability to adapt to the environment, increase their ability to fight and compete, and support character development. It also provides solidarity, harmony and peace between communities and nations [2]. Physical activity is considered as a key factor for a healthy physical and mental development of children [3,4]. The prevalence of overweight/obesity in children increases the risk of developing various chronic diseases in the later years because physically inactive children are not expected to have an active life in the following years [5]. The level of activity may also imply normal growth or potential health problems. Inactive lifestyle and aging increase the risk of many diseases. Physically active individuals have good body composition and have less health problems [6].

It has been known that the participation in sports and physical activities in childhood period is important for improvement in general public health [7]. Having a sporting habit in childhood period minimizes the probable physical, metabolically and functional health risks in future. In addition to children's sedentary lifestyle, irregular fast food consumption habit leads to many health problems. Sports, physical activity and exercise programs that are applied together with the diet are known to reduce many health problems in children [8,9]. Physical fitness is closely related to both health and skills, because it is one of the most important factors affecting the individual's daily life, activity and sporting efficiency. As a result of physical activity reduced by sports scientists in research, flexibility, endurance, power and speed performances have been decreased $[10,11]$. The success of the athlete depends on the improvement of speed, flexibility and leap technique performance [12-14]. The motoric skills of athletes such as strength, endurance, coordination, agility, speed, balance in movements like running, jumping, hitting, spinning and throwing can be expected to develop through the increase in core strength and stability [15]. Sport plays an important role both physically and mentally for younger generations. Physical trainings and sports are complementary and basic educational elements in civil and modern societies [16]. Updated values are required for the target population to assess physical fitness. Due to the methodological differences in the physical fitness assessment protocols, it is very complicated to compare and interpret between different populations [4,17]. Monitoring children's physical fitness also contributes to the preventive services of health agencies. Physical fitness and tests reflect the relationship between health, sport and physical activity. 
Standardization studies are used in several areas [18]. Eurofit tests applied to children of different age groups; it provides data on the anatomical and functional properties of general health conditions and exercise habits $[2,19]$.

Simultaneous assessment of anthropometric parameters and motor skills will provide more accurate information about children's developmental processes, but it is not well known whether there is a relationship between anthropometric parameters and motor abilities in children with gender and age differences. The fact that the physically active lifestyle becomes a popular at an early age is important in terms of creating a healthy society in the future. The aim of this study is to compare the motor performance of children by gender and age.

\section{Methods}

\subsection{Participants}

A total of 160 children ( 80 girls and 80 boys) participated in this study voluntarily. The families and school administrators of the children were informed in detail about the study and their approvals were received. Participants and their families were informed in detail before the study. All children and their parents were thoroughly informed about the purposes and contents of the study.

\subsection{Statistical Analyses}

All data were analyzed IBM SPSS 22 . The data have been given in the way of mean, standard deviation (SD), minimum (Min) and maximum (Max). Statistical significance level is determined as 0.05 and 0.001 . For statistical analysis, one-way analysis of variance (One-Way ANOVA) and LSD (Least Significant Difference) being one of the multiple comparison tests were made.

\subsection{Data Collecting Tools}

Anthropometric measurements and physical fitness tests were performed in a specific order and in accordance with the guidelines. Girls and boys attended sportswear with all measurements. The tests were carried out by the researcher at the indoor sports hall in May 2016. Two measurements were taken for each test and the appropriate was considered.

The physical measurements like heights and body weights; and motoric properties like flexibility, arm movement speed, balance, standing long jump, arm strength, sit-up and speed of the participating children were measured.

\subsubsection{Measurement of Body Weight}

The weight of the children was measured with Tanita

\section{A Japan a sensitivity of \pm 0.1 kilogram (kg)}

\subsubsection{Measurement of Body Height}

Standing height was measured without shoes with the child standing on the platform of the Harpenden stadiometer (Holtain UK). The subject's head was positioned in the Frankfort horizontal plane.

\subsubsection{Sit and Reach Test}

The length of the testing tool was 35 centimeters $(\mathrm{cm})$, width $45 \mathrm{~cm}$, and height $32 \mathrm{~cm}$. The upper surface length was $45 \mathrm{~cm}$, and with $45 \mathrm{~cm}$. The upper surface was $15 \mathrm{~cm}$ outside the surface to which the legs were based on. The $0-50 \mathrm{~cm}$ measurement tape was defined with parallel lines that were $5 \mathrm{~cm}$ far from each other in the upper surface. Children sit and place their bare feet properly on the test instrument. Both knees must be locked and pressed flat on the ground. The subject extends as far as possible along the measuring line when the palms are facing down, and the hands are on top of each other or side by side. They hold that position for a one-two seconds while the distance is recorded. The test was repeated twice, and the highest value was recorded.

\subsubsection{Flamingo Balance Test}

The flamingo balance test was used to measure the body balance. A $50 \mathrm{~cm}$ long, $4 \mathrm{~cm}$ high and $3 \mathrm{~cm}$ wide iron bar was used for the measurement. During this test, the subject tries to keep the bare foot on the long axis of the beam as long as possible in a manner similar to that of a flamingo. When the balance deteriorates, the time is stopped and the total balance disturbances within 1 minute are counted as the test result.

\subsubsection{Plate Tapping}

Test was performed to touch the discs to measure arm movement speed. The subject tries to quickly touch the two discs with the preferred hand. Discs with a diameter of 20 $\mathrm{cm}$ are $80 \mathrm{~cm}$ apart. The number of the touches was recorded.

\subsubsection{Standing Long Jump Test}

For the standing long jump test, the participant student stood feet next to each other, the tips of the toes were kept before the jumping line; and jumped forward as far as s/he could by swinging hands to and fro and by bending the knees. Two trials were made, and the best value was recorded.

\subsubsection{Sit-up 30 Seconds Test}

The purpose of this test is to perform as many sit-ups as possible within 30 seconds (sec). Tilt the feet straight and lean on the reins, as the feet are leaning against the ground and held by a partner. Fingers should be locked behind the head. In the 'Go to' command, lift the chest up, so that the upper body will be vertical, then return to the ground; continue for $30 \mathrm{sec}$ you need to touch the floor back to each seat. 


\subsubsection{Bent Arm Hang test}

The participant is assisted, the body is lifted to a height, so the jaw is at the same level as the horizontal rod. The rod is grasped with the shoulder width of the hands, using a palm grip. Starts when the athlete is released. They should try to keep this position as long as possible. The timing stops when the person's jaw falls below the bar's level.

\subsubsection{Meter Sprint}

The children ran at a maximum speed of 30 meters. Running time was recorded with chronometer. Two attempts were made, and the best time was recorded.

\section{Results}

In table 1 compared children's anthropometric characteristics according to gender and age level. In table 2, children's motor performances were compared according to gender and age level.

The data in this study are as follows respectively; in girls and boys 11 years old, the heights were $144.68 \mathrm{~cm}$ and $143.04 \mathrm{~cm}$, the body weights were $40.01 \mathrm{~kg}$ and $36.26 \mathrm{~kg}$, in the 12 years old girls and boys the heights were 147.93 $\mathrm{cm}$ and $142.23 \mathrm{~cm}$ and the body weights $42.81 \mathrm{~kg}$ and $37.59 \mathrm{~kg}$.

Table 1. Anthropometric characteristics of children's according to gender and age level

\begin{tabular}{|c|c|c|c|c|c|c|c|}
\hline & Categories & $\mathrm{N}$ & Mean & SD & Min & Max & $\mathrm{F} / \mathrm{lsd}$ \\
\hline \multirow{4}{*}{ Height (cm) } & 11 age/girls (1) & 38 & 144.68 & \pm 3.5 & 140.00 & 151.00 & \multirow{4}{*}{$\begin{array}{c}17.21 * * \\
1<3 \\
2,3>4\end{array}$} \\
\hline & 11 age/boys (2) & 39 & 143.04 & \pm 2.76 & 140.00 & 148.00 & \\
\hline & 12 age/girls (3) & 41 & 147.93 & \pm 5.1 & 143.00 & 158.00 & \\
\hline & 12 age/boys (4) & 42 & 142.23 & \pm 3.25 & 136.00 & 148.00 & \\
\hline \multirow{4}{*}{ Body weights (kg) } & 11 age/girls (1) & 38 & 40.01 & \pm 2.78 & 36.00 & 48.00 & \multirow{4}{*}{$\begin{array}{c}30.27^{* *} \\
1<3 \quad 2<1,3 \\
4<3\end{array}$} \\
\hline & 11 age/boys (2) & 39 & 36.26 & \pm 2.56 & 33.00 & 41.00 & \\
\hline & 12 age girls (3) & 41 & 42.81 & \pm 4.37 & 36.00 & 50.00 & \\
\hline & 12 age/boys (4) & 42 & 37.59 & \pm 3.03 & 32.00 & 45.00 & \\
\hline
\end{tabular}

$* * \mathrm{p}<0.001$

Table 2. Children's motor performances according to gender and age level

\begin{tabular}{|c|c|c|c|c|c|c|c|}
\hline & Categories & $\mathrm{N}$ & Mean & $\mathrm{SD}$ & Min & Max & $\mathrm{F} / \mathrm{lsd}$ \\
\hline \multirow{4}{*}{ Sit and reach test $(\mathrm{cm})$} & 11 age/girls (1) & 38 & 8.56 & \pm 1.04 & 7.00 & 11.00 & \multirow{4}{*}{$\begin{array}{l}21.13^{* *} \\
1,3<2,4\end{array}$} \\
\hline & 11 age/boys (2) & 39 & 11.84 & \pm 2.88 & 7.00 & 16.00 & \\
\hline & 12 age/girls (3) & 41 & 9.06 & \pm 1.29 & 7.00 & 12.00 & \\
\hline & 12 age/boys (4) & 42 & 11.01 & \pm 2.47 & 7.00 & 16.00 & \\
\hline \multirow{4}{*}{$\begin{array}{l}\text { Flamingo balance test } \\
\text { (errors) }\end{array}$} & 11 age/girls (1) & 38 & 6.9 & \pm 1.32 & 5.00 & 9.00 & \multirow{4}{*}{$\begin{array}{c}15.14^{* *} \\
1<2,3,4 \\
2<3,4\end{array}$} \\
\hline & 11 age/boys (2) & 39 & 7.92 & \pm 1.38 & 6.00 & 10.00 & \\
\hline & 12 age/girls (3) & 41 & 9.17 & \pm 2.24 & 6.00 & 15.00 & \\
\hline & 12 age/boys (4) & 42 & 8.81 & \pm 1.30 & 7.00 & 11.00 & \\
\hline \multirow{4}{*}{$\begin{array}{l}\text { Plate tapping } \\
\quad(\mathrm{sec})\end{array}$} & 11 age/girls (1) & 38 & 8.56 & \pm 0.98 & 7.00 & 11.00 & \multirow{4}{*}{0.52} \\
\hline & 11 age/boys (2) & 39 & 8.45 & \pm 0.80 & 8.00 & 10.00 & \\
\hline & 12 age/girls (3) & 41 & 8.37 & \pm 0.74 & 7.00 & 9.00 & \\
\hline & 12 age/boys (4) & 42 & 8.56 & \pm 0.74 & 8.00 & 10.00 & \\
\hline \multirow{4}{*}{ Sit-up $30 \mathrm{sec}$} & 11 age/girls (1) & 38 & 12.31 & \pm 2.41 & 8.00 & 15.00 & \multirow{4}{*}{$\begin{array}{l}13.54^{* *} \\
1,3>2,4\end{array}$} \\
\hline & 11 age/boys (2) & 39 & 10.01 & \pm 1.40 & 8.00 & 14.00 & \\
\hline & 12 age/girls (3) & 41 & 12.65 & \pm 2.18 & 8.00 & 15.00 & \\
\hline & 12 age/boys (4) & 42 & 10.15 & \pm 1.30 & 8.00 & 14.00 & \\
\hline \multirow{4}{*}{$30 \mathrm{~m}$ sprint $(\mathrm{sec})$} & 11 age/girls (1) & 38 & 6.05 & \pm 0.29 & 5.18 & 6.35 & \multirow{4}{*}{$\begin{array}{c}4.03^{*} \\
2,4<1,3\end{array}$} \\
\hline & 11 age/boys (2) & 39 & 5.88 & \pm 0.37 & 5.18 & 6.25 & \\
\hline & 12 age/girls (3) & 41 & 6.04 & \pm 0.29 & 5.18 & 6.35 & \\
\hline & 12 age/boys (4) & 42 & 5.78 & \pm 0.29 & 5.24 & 6.25 & \\
\hline \multirow{4}{*}{ Standing long jump $(\mathrm{cm})$} & 11 age/girls (1) & 38 & 148.92 & \pm 4.10 & 135.00 & 165.00 & \multirow{4}{*}{$\begin{array}{l}13.04 * * \\
1,4>2,3\end{array}$} \\
\hline & 11 age/boys (2) & 39 & 143.03 & \pm 3.75 & 135.00 & 149.00 & \\
\hline & 12 age/girls (3) & 41 & 143.95 & \pm 5.89 & 130.00 & 151.00 & \\
\hline & 12 age/boys (4) & 42 & 149.17 & \pm 3.64 & 135.00 & 151.00 & \\
\hline \multirow{4}{*}{ Bent arm hang test (sec) } & 11 age/girls (1) & 38 & 16.67 & \pm 5.41 & 13.00 & 19.00 & \multirow{4}{*}{$\begin{array}{l}61.07 * * \\
1,3>2,4\end{array}$} \\
\hline & 11 age/boys (2) & 39 & 19.15 & \pm 1.89 & 14.00 & 21.00 & \\
\hline & 12 age/girls (3) & 41 & 18.88 & \pm 4.39 & 14.00 & 21.00 & \\
\hline & 12 age/boys (4) & 42 & 19.59 & \pm 1.69 & 15.00 & 22.00 & \\
\hline
\end{tabular}

$* \mathrm{p}<0.05 * *_{\mathrm{p}}<0.001$ 
In this study, the parameter results are as follows according to the genders of the 11 ages children: in male and female children's; sit and reach test $8.56 \mathrm{~cm}$ and 11.84 $\mathrm{cm}$, flamingo balance test 6.90 errors and 7.92 errors, plate tapping $8.56 \mathrm{sec}$ and $8.45 \mathrm{sec}$, sit-up 12.31 and 10.01, 30 meter speed $6.05 \mathrm{sec}$ and $5.88 \mathrm{sec}$, long jump $148.92 \mathrm{~cm}$ and $143.03 \mathrm{~cm}$, bent arm hang test 16.67 and 19.15, respectively. The parameter results are as follows according to the genders of the 12 ages children: in male and female children's; sit and reach test $9.06 \mathrm{~cm}$ and 11.01 $\mathrm{cm}$, flamingo balance test 9.17 errors and 8.81 errors, plate tapping $8.37 \mathrm{sec}$ and $8.56 \mathrm{sec}$, sit-up $30 \mathrm{sec} 12.65$ and 10.15 , 30 meter speed $6.04 \mathrm{sec}$ and $5.78 \mathrm{sec}$, standing long jump $143.95 \mathrm{~cm}$ and $149.17 \mathrm{~cm}$, bent arm hang test $18.88 \mathrm{sec}$ and $19.59 \mathrm{sec}$, respectively.

\section{Discussion}

Physical activity is a determinant part of a healthy lifestyle. Physical activate is associated with the decreased risk of cardiovascular diseases, metabolic syndrome, adiposity and obesity, and a variety of physiological and psychological problems [20]. Motor skills in girls and boys differ in performance values. Aybek et al. [21] in a study was found motivation for the lesson higher in boys than in girls.

Chasan et al. [2] in a study conducted with children aged 8-11 years, found that the body weight of girls is higher than that of boys. In some studies, boys and girls aged between 7 and 10 years have been reported to increase in body weight at the same rate [18]. There were differences in height and body weights between the 11 and 12 ages of in this study $(\mathrm{p}<0.001)$. In a study performed by Karakaş et al. [22] the body weight of 11-year-old girls was found to be $34.5 \mathrm{~kg}$ and boys $33.4 \mathrm{~kg}$. According to literature, this research results are higher. The increase in girls' body weight is more than boys, which can be explained as developmental differences during adolescence. The standard of living and cultural status of society can affect physical development. The fact that 12-year-old girls' height and weight are higher than boys can be associated with early adolescence.

There is a statistically significant difference in the values of the sit and reach test according to gender $(\mathrm{p}<0.001)$. The values of girls are lower than boys. In the study, it was determined that boys were more flexible than girls between 11 and 12 years of age. Yücel et al. [18] found that gender and age factors had a common effect on the degree of flexibility of children. Gonzales et al. [23] found $13.3 \mathrm{~cm}$ and $12.5 \mathrm{~cm}$ values for the sit and reach test for boys aged 11 and 12 in a study. Girls of the same age had $17.3 \mathrm{~cm}$ and $19 \mathrm{~cm}$ values for sit and reach test.

The number of errors in the flamingo balance test shows a statistically significant result depending on age $(p<0.001)$. The values of the 11 age group data are lower than the values of the 12 age group data. In relation to the effects of adolescence due to age progression, balance disorders are emerging. Gonzales et al. [23] found 9.3 and 9.5 values for the flamingo test for boys aged 11 and 12 . Girls of the same age had 8.7 and 9.4 values for flamingo test.

Plate taping test result values are not statistically significant according to gender or age $(\mathrm{p}>0.001)$. Gonzales et al. [23] found the values of $14.7 \mathrm{sec}$ and $14.0 \mathrm{sec}$ in the plate-taping test for boys aged 11 and 12 years. Girls of the same age had $14.3 \mathrm{sec}$ and $13.4 \mathrm{sec}$ values for plate taping test.

Imamoğlu and Çoknaz [24] found that girls showed higher values than males in sit- and reach test, flamingo test and plate tapping test 12-year-old Turkish children.

Sit-up test data are examined; it is seen that there is a statistically significant difference according to gender $(p<0.001)$. The values of girls are higher than boys. The reason for this is that girls have entered the adolescence period earlier than boys in these age groups. When the test results of girls and boys are evaluated within themselves, the test results of the 12 year old are mathematically higher than those in the 11-year-age group. Gonzales et al. [23] found the values of 20.5 and 21.9 for the sit -up test for boys aged 11 and 12 years. Girls of the same age had 18.4 and 19.4 values for sit-up test. According to the results of the study by Yücel et al. [18] there is a faster increase in the performance of the girls than in the boys. In this study, it is understood that the sit-up degrees of girls are higher than boys.

The sprint test data of 30 meters expresses statistical significance in terms of gender $(\mathrm{p}<0.001)$. Boys' sprint times are lower than girls. Acceleration and the protection of the current speed are important factors in the 30 meter sprint test. In a study by Gül et al. [25] a significant difference was found between the values of 30 meter sprinting speed in children's male wrestlers by years. There is a significant difference in this study between 30 meter sprint values according to sex, not age. This can also be attributed to the fact that girls develop earlier than boys. The difference in 30 meter sprint running and standing long jump values may be due to ages as well as differences for the genetic features. The genetic features are effective on the 30 meter sprints [26]. In the study of Ziyagil and İmamoğlu [27] it is stated that women have less muscle mass than those of men, but in this study, the fact that the children were in the 11 and 12 age caused no the same idea to be supported.

There is a statistically significant difference in standing long jump test results $(\mathrm{p}<0.001)$. Long jump distances of 12-year-old boys with 11-year-old girls are more than 11-year-old boys and 12-year-old girls. In a study by Gül et al. [25] a significant difference was found no between the values of standing long jump in children's male wrestlers by the years. Gonzales et al. [23] found the values of 141.4 $\mathrm{cm}$ and $148.9 \mathrm{~cm}$ for the broad jump test for boys aged 11 and 12 years. Girls of the same age had $129 \mathrm{~cm}$ and $132 \mathrm{~cm}$ 
values for broad jump test. İmamoğlu and Çoknaz [24] found that boys showed better values than girls in standing long jump and bent arm hang test values.

A statistically significant difference is observed in bent arm hang test values $(p<0.001)$. The hanging times of the boys are higher than the girls. Gonzales et al. [23] found the values of $10.4 \mathrm{sec}$ and $12.8 \mathrm{sec}$ in the bent arm hang test for boys aged 11 and 12 years. Girls of the same age had 6.4 $\mathrm{sec}$ and $7 \mathrm{sec}$ values for bent arm hang test.

Tomkinson et al. [28] in a study showed that boys performed better than girls on muscular strength, muscular power, muscular endurance, speed-agility and cardiorespiratory fitness tests, but worse on the flexibility test. Especially at a young age, the fitness of boys has developed faster than girls.

\section{Conclusions}

Anthropometric characteristics and motor performance test values of the children according to their ages and genders were within normal limits. Physical characteristics and motor performance parameters vary by age and gender.

The fact that the performances of the participants in the sporting events are similar will increase the competition. Therefore, to considered the differences physical characteristics and motor performance of children according to age and gender in planning sportive activities for health and education will increase efficiency and be beneficial. Families and coaches can make successful planning if they know the differences in the physical characteristics and motor performances of children according to age and gender.

\section{Conflict of Interest}

The authors declare no conflict of interest.

\section{REFERENCES}

[1] M.B. Hoos, W.J. Gerver, A.D. Kester, K.R. Westerterp. Physical activity levels in children and adolescents, Int $\mathbf{J}$ Obes Relat Metab Disord, Vol.27, No.5, 605-9, 2003. DOI: 10.1038/sj.ijo.0802246

[2] K. Chasan, İ. Toksöz, N. Sut. Physical condition evaluation of students between 8-11 ages of age by eurofit tests, Turkish Journal of Sports Medicine, Vol.45, No.1, 2010.

[3] M. Dencker, L.B. Andersen. Health-related aspects of objectively measured daily physical activity in children, Clin Physiol Funct Imaging, Vol.28, No.3, 133-44, 2008. DOI: 10.1111/j.1475-097X.2008.00788.x.

[4] F.B. Ortega, E.G. Artero, J.R. Ruiz, V. España-Romero, D. Jiménez-Pavón, G. Vicente-Rodriguez, et al. Physical fitness levels among European adolescents: the HELENA study, Br J Sports Med, Vol.45, No.1, 20-9, 2011. DOI: 10.1136/bjsm.2009.062679.

[5] C. Milanese, O. Bortolami, M. Bertucco, G. Verlato, C. Zancanaro. Anthropometry and motor fitness in children aged 6-12 ages, Journal of Human Sport \& Exercise, Vol.5, No.2, 265-279, 2010. DOI: 10.4100/jhse.2010.52.14

[6] W.L. Haskell, M. Kiernan. Methodologic issues in measuring physical activity and physical fitness when evaluating the role of dietary supplements for physically active people, Am J Clin Nutr, Vol.72, No.2, 541S-50S, 2000. DOI: $10.1093 / \mathrm{ajcn} / 72.2 .541 \mathrm{~S}$.

[7] M. Hekim. Health problems caused by sedentary living style -a global problem- and the importance of physical activity in prevention of the health problems caused by sedentary living style, 2nd International Davraz Congress Proceedings Book, Isparta, Turkey, 2363-2371, 2014.

[8] H. Altunkan. The prevalence of obesity in children ages 6-19 in Karaman City, Turkey. Journal of Medicinal Researches, Vol.11, No.1, 6-11, 2013.

[9] V. Ayan. A study on the relationship between the performance characteristics and the body mass index of 810 age old children, Asian Journal of Education and Training, Vol.4, No.2, 108-113, 2018. DOI: 10.20448/journal.522.201 8.42.108.113

[10] S. Houwen, C. Visscher, E. Hartman, K.A.P.M. Lemmink. Test-retest reliability of eurofit physical fitness items for children with visual impairments, Pediatiric Exercise Science, Vol.18, No.3, 300-313, 2006. DOI: 10.1123/pes.18.3.300

[11] C. Riddoch, B. Boreham. Physical activity, physical fitness and childrens health: Current concepts. In: N. Armstrong, W. Van Mechelen, editors, Paediatric exercise sience and medicine Oxford, UK, Oxford University Pres., 243-252, 2000.

[12] O. İmamoğlu, R. İmamoğlu, O. Sarioğlu, I. Can, F. Yamaner. The comparison of fatigue and recovery levels in footballers of different categories through the repetitive sprint test, 7-10 Februar, the 3rd İnternational Conference on Sports and Exercise Science, Bangkok, Thailand, 2012.

[13] R. İmamoğlu, İ. Can, M. İmamoğlu, A.Y. Albayrak, O. İmamoğlu. Comparison of some anthropometric, physiological and motor performance factors in professional and amateur soccer players, 4th International Conference on Sports and Exercise Science: Well-Being Well Beyond Sport and Exercise, Bangkok/Tailand. 358, 2013.

[14] O. İmamoğlu, M. Çebi, M. Yıldız. The research of consecutive sprint, jump and leg strength relationships in u15 football players, The Journal of International Social Research, Vol.11, No.58, 913-918, 2018. DOI: 10.17719/jisr.2018.2604

[15] O. Sever, E. Zorba. Comparison of effect of static and dynamic core exercises on speed and agility performance in soccer players, Isokinetics and Exercise Science, Vol.26, No.1, 29-36, 2018. DOI: 10.3233/ies-171120

[16] E. Şimşek, Z.B. Aktuğ, Ç. Çelenk, T. Yılmaz, E. Top, E. Kara. The evaluation of the physical characteristics of 
football players at the age of 9-15 in accordance with age variables, International Journal of Science Culture and Sport (IntJSCS), Vol.1, 460-468, 2014. DOI: 10.14486/IJSCS118

[17] F.B. Ortega, J.R. Ruiz, M.J. Castillo, L.A. Moreno, M. González-Gross, J. Wärnberg, et al. Low level of physical fitness in Spanish adolescents. Relevance for future cardiovascular health (AVENA study), Rev Esp Cardiol, Vol.58, No.8, 898-909, 2005. DOI: $10.1016 / \mathrm{S} 1885-5857(0$ 6)60372-1

[18] O. Yüksel, K. Tamer, G. Çalışkan. Evaluate the physical fitness levels of Turkish primary school male and female children between 7-14 ages, Ovidius University Annals, Series Physical Education and Sport/Science, Movement and Health, Vol.14, No.2, 585-593, 2014.

[19] Ö. Erikoğlu, N.A. Güzel, M. Pense, G.E. Örer. Comparison of physical fitness parameters with eurofit test battery of male adolescent soccer players and sedentary counterparts, International Journal of Science Culture and Sport (IntJSCS), Vol.3, No.3, 43-52, 2015. DOI: 10.14486/IntJSCS434

[20] S.M. Tremblay, G.A. LeBlanc, E.M. Kho, T.J. Saunders, R. Larouche, R.C. Colley, et al. Systematic review of sedentary behavior and health indicators in school-aged children and youth, Int J Behav Nutr Phys Act, Vol.8, 2011. DOI: $10.1186 / 1479-5868-8-98$.

[21] A. Aybek, O. İmamoğlu, M.Y. Taşmektepligil. An assessment of the attitudes of students towards physical education lesson and extracurricular activities, Journal of Sports and Performance Researches, Vol.2, No.2, 51-59, 2011.

[22] S. Karakaş, Ö.F. Cihan, A. Kavakl1, C. Eroğlu, A. Aluçlu. Relationship between age, height and sitting height of primary school children in Malatya urban area, Journal of Adnan Menderes University Medical Faculty, Vol.3, No.2, 15-18, 2002.

[23] R.G. Gonzales, M.S. Lopez, A.O. Bravo, M.S. Martinez, V.M. Vizcaino. Physical fitness in Spanish schoolchildren aged 6-12 ages: reference values of the battery eurofit and associated cardiovascular risk, J Sch Health, Vol.84, No.10, 625-635, 2014. DOI: 10.1111/josh. 12192.

[24] O. İmamoğlu, H. Coknaz. Research of the physical education courses and students' physical developments in the elementary school and middle school education program, Journal of Physical Education and Sport Sciences Atatürk University, Vol.4, No.2, 5-11, 2002.

[25] M. Gül, O. İmamoğlu, M. Özdal, A. Doğan. Annual changes of physical and physiological features of Wrestlers staying in wrestling training center, II. International traditional and olympic wrestling symposium, Kahramanmaraş, Turkey, 21, 2012.

[26] Y. Ağaoğlu, H. Eker, O. İmamoğlu. Effect of knee strength and body mass index on $30 \mathrm{~m}$ and $1500 \mathrm{~m}$ running performance, Mustafa Kemal University Journal of Social Sciences Institute, Vol.6, No.11, 402-421, 2009.

[27] M.A. Ziyagil, O. İmamoğlu. The effects of repeat sprints on mean smile and minute heart rate of male and female soccer players, Football Science and Technology Review, Vol.4, 3-10, 2000.

[28] G. Tomkinson, K.D. Carver, F. Atkinson, N.D. Daniell, L.K.
Lewis, J.S. Fitzgeral, et al. European normative values for physical fitness in children and adolescents aged 9-17 ages: results from 2779165 Eurofit performances representing 30 countries, Br J Sports Med, Vol.52, No.22, 2018. DOI: 10.1136/bjsports-2017-098253. 